\title{
Language Disabilities: Myths and Misconceptions vs. Reality
}

\author{
George S. Mouzakitis \\ Educational Organization e-DEKA
}

Greece

\section{Introduction}

It is strongly supported that the involvement with the persons who encounter various problems due to certain disabilities in no way can be claimed to be a philanthropic pursuit nor to be limited only to this form of support. It is true that a support based on volunteering work includes organization of social gatherings for disabled persons in order to strengthen their belief in their capacity for work, their ability to behave independently, to be included in the workforce of their country and enjoy the recognition of their environment as concerns the positive traits of their character (Pato,B.,2010)

Evidently, the measures which should be taken by official state services in the line with the expressed support of ordinary people not only will contribute to the relief of persons in need, but, also, will support national efforts to meet the crucial situation as a result of the economic crisis almost worldwide.

The Employment and Social Affairs Directory of EU, in a survey on disability matters (2007) identified that the $74 \%$ of the EU27 population thinks that more people with disabilities are needed in the work place. The crucial point of the employment indicators, and the involvement of persons with disabilities in the labour market is the disputable figures of prevalence

A survey has been, also, conducted by my research team almost two years ago,for this study among a randomly selected sample of 138 persons concisted of 70 males and 68 females aged between 25 to 37 years old employeed in small and medium enterprises (SME).The problem statement was:" It is claimed that more people with disabilities are required in our today's labour market. Do you agree?" Please tick one of the following five options .The responses are shown in the following table 1.

Consequently, it is very promising that an increasing interest in recruiting persons with disabilities to the workforse will be an effective treatment of these persons who constitute the "major minority" as it will be proved in the following pages of this paper. Besides, there are plenty of jobs ranging from laborers, gardeners and upholsterers through auxiliary services to unskilled workers. It is clear that to achieve these goals, persons with disabilities are required to attend tailor-made training courses supplied by specific schools with the use of educational tools adapted to meet the learning requirements of these individuals. From 
the economic point of view it is more interesting to pay for increasing the productivity of the work force rather than paying unemployment benefits which will provide social benefits to disabled individuals but will not produce any economic output.

\begin{tabular}{|c|c|c|}
\hline SAMPLE & 138 & $100.00 \%$ \\
\hline \multicolumn{3}{|c|}{ RESPONSES } \\
\hline I quite agree & 58 & $42.03 \%$ \\
\hline I agree & 50 & $36.2 \%$ \\
\hline I doubt & 05 & $3.62 \%$ \\
\hline I disagree & 20 & $14.50 \%$ \\
\hline I do not know & 5 & $3.62 \%$ \\
\hline
\end{tabular}

Table 1. People with disabilities accepted in the work place. Sourse: Author's research team

\section{Communication problems}

Effective communication means that the person, someone communicates with, totally understands the speaker. Verbal and written messages are conveyed by means of linguistic systems or symbols, or else words, which represent a thought, a concept, an object or an experience. (Mandy, H (2009) The system requires a receiver and a sender operating (tuned) in the same wave band. Linguistically, the wave band is the word. In case communication process uses words of confusing or unknown meaning there is no communication and hence understanding. Unfortunately, this negative phenomenon happens in the area of persons with disabilities.

For decades various terms about 'Special Education" are used based on traditional practice rather than a scientific term to describe the situation. The term "special" is used to characterize the educational process of persons with disabilities. Yet, "special " means distinguished, better than normal. Vocational Schools offer many special courses, say for plumbers, electricians or other professionals. All these people are not necessarily disabled Misused terms and terms recommended as appropriate are cited here below (Table 2).

\begin{tabular}{|c|c|c|c|}
\hline Misused Terms & Recommended & Misused Terms & Recommended \\
\hline Special Education & $\begin{array}{c}\text { Alternative } \\
\text { Education }\end{array}$ & $\begin{array}{c}\text { Mental retardation } \\
\text { (Low IQ) }\end{array}$ & $\begin{array}{c}\text { Developmental } \\
\text { Disabilities }\end{array}$ \\
\hline Special Needs & Particular Needs & $\begin{array}{c}\text { Physically } \\
\text { Handicapped }\end{array}$ & $\begin{array}{c}\text { Physically } \\
\text { Challenged }\end{array}$ \\
\hline $\begin{array}{c}\text { Handicapped } \\
\text { (offensive term) }\end{array}$ & $\begin{array}{c}\text { Impaired } \\
\text { (accepted term) }\end{array}$ & $\begin{array}{c}\text { Exceptional } \\
\text { persons } \\
\text { (Extremely good) }\end{array}$ & $\begin{array}{c}\text { Persons with } \\
\text { Disabilities }\end{array}$ \\
\hline
\end{tabular}

Table 2. Misused and recommended terms for persons with disabilities, Source: Author's proposals 
As seen in the above table, the difference between the traditional terms usage and the purely scientific ones is very important in communication. The use of terms not easily understood or creating confusion may have serious impacts on the lives of persons with disabilities. For example, the use of the terms handicapped, exceptional. retarded and other result to confusion. It is, certainly, for this reason that the most authentic world organizations refer to persons with disabilities The United Nations Organization (UNO) in 2006, the World Health Organization (WHO) in 2001, the Council of Europe in 2006, and the Employment and Social Affairs of EU27 in 2010 define persons of any form of impairment as disability .The paradox about the terminology used is that most of the member countries of these world organizations, though signatories of the relative agreements continue to use terminology which was adopted many decades ago.

Presumably, they stick to the traditional terms which have been in use since decades, instead of using the scientific terms which from the communicative point of view are more effective. It is, therefore, important that definitions used to describe persons of any sort of impairments should be universally accepted to ensure clear understanding. In science, there is not a matter of traditional pursuit, but a purely scientific discourse. Tradition is a longestablished way of defining the various terms related to persons with disabilities. On the other hand, scientific ways of defining terms conform with the principles or methods used in describing specific situations.

During the early years in the history of "Special Education" various scientists, mainly psychologists, classified people into groups according to their disabilities. As a result of this movement, the following categories have been registered by Heward \& Ortansky. (1984)

- $\quad$ Learning Disabilities

- Emotional Disturbance

- $\quad$ Speech and Language Disorders

- Hearing Impairment

- Visual Impairment

- Physical Handicaps

- Mental Retardation

- Behavior Disorders

The lack of linguists in the process of defining the various impairments is obvious and has resulted to the creation of misunderstandings among everybody concerned with special education A typical example of the confusion created by the variety of definitions concerning the various disabilities among the EU27 countries is the dicision of the European Union to assign to the Brunel University (Mablett, D.,2009) to perform a comparative analysis of the definitions of disability used in the social security and employment area across the European Union member states

What is astonishing in the whole defining process is that the predominant term of these persons with disabilities is exceptional persons. A simple survey in five on-line dictionaries of English Language randomly selected revealed the confusion the term exceptional creates to parents, educators, medical people and others because the form exceptional has contrasting meanings as explained in the dictionaries: 
- Dictionary com

- $\quad$ Being unusually excellent, superior. ( an exceptional violinist) [+]

- Being physically ore especially mentally handicapped. Special schooling is required. [-]

- The free dictionary

- Having much more than average intelligence, ability or skills. (an exceptional memory) $[+]$

- Deviating widely from the norm as of physical, mental ability. [-]

- Answers.com

- Well above average, extraordinary. (an exceptional talent) [+]

- Below normal in intelligence [-]

- Macmillan Dictionary

- Extremely good or impressive in a way that is unusual [-]

- Merrian Webster

- Better than average, superior ( an exceptional skill) [+]

- Deviating from the norm, as having above or below average intelligence. [+/-]

Now picture that you receive a letter from your daughter's school informing you that "your daughter is exceptional". What will you do? Will you jump for joy? or will you feel bitterness?

\section{Historical review}

References related to aid, support and medical treatment of individuals in need are traced even during the dark periods of mankind as cited by Winzer, M., (1993). From 1500 to 1662 four events have been considered the cornerstones in the history of special education.

- Marginal improvements for handicapped persons appear in 1500.

- $\quad$ Pedro Ponce de Leon undertook the education of handicapped persons in Spain in 1578.

- Jean Pablo Bonet wrote the first book on special education in 1620.

- The Royal Society of London supports research into the nature of language and the teaching of deaf and blind individuals in 1662.

- $\quad$ During the $17^{\text {th }}$ century European pioneers were involved in a variety of attempts to educate disabled persons.

Moreover, the first school for blind children is recorded in UK in 1791, whereas the first school for deaf was established in USA in 1817 under the name of American Asylum for the Education of the Deaf and Dumb In the 1800s the education of disabled persons was the responsibility of individuals supported by charities, hospitals, philanthropists etc following a system tending to the isolation of disabled persons.

By the end of the $18^{\text {th }}$ century, education for disabled children was accepted as a branch of education under the name of Special Education.

Following the change of attitude toward people with disabilities during the end of the 18th century in the USA, reformers founded schools to educate children with a variety of disabilities. (Alton, G.,(2001) The compulsory education for normal children (1900) was extended to all children in England in 1913 and in USA in 1918. Beginning in the late 1960 and early in 1970 parents and advocates for students with disabilities began to use the 
courts trying to force the states to provide an equal educational opportunity to these students (Yell, M.,(2004).

The compulsory education for normal children (1909) was extended to all children in England in 1913 and in USA in 1918.

Beginning in the late 1960 and early in 1970, parents and advocates for students with disabilities began to use the courts trying to force the states to provide an equal educational opportunity to these students. (Yell, M.,(2006). Among these e cases the following are worth mentioning:

- Established the right of all children to an equal opportunity to education.

- Declared the track system for Special Education placement unconstitutional because of discrimination against black and poor children.

- Supported the right of individuals to have appropriate treatment within state institutions.

In the period of 1958 to 1975, Heward, W. \& Orlansky, D., (op.cit,) reported that four important public laws out of the twelve which were passed refer to:

- P.L. 85-926 (1958): Provision of funds for training professionals to train teachers of the intellectually disabled.

- P.L. 87-276 (1961) Funds for training professionals to train teachers of the deaf.

- P.L. 88-164 (1963) Funds for training teachers of other handicapped persons, including retarded.

- P.L. 91-320 (1969) Definition of Learning Disabilities and provision of funds for statelevel programmes for learning disabilities.

The emergence of initiatives related to persons with disabilities towards the integration accomplished in the $20^{\text {th }}$ century followed a fascinating pathway from the 16th century in Spain through the Age of Enlightenment in 17th century France and England to $18^{\text {th }}$-century issues in Europe and North America.(Winzer, M., op.cit)

\section{Classification and definition of terms}

Following the decisions of all world organizations to refer to all forms of impairments as disabilities, a term which is readily accepted by the legal associations of persons with disabilities, it is more than confusing to continue to use this term when referring to all the forms of this learning problem. I would propose that we use instead of the term learning disabilities for the whole category the term learning impairments.

Then, learning impairments will consist of slow learners, learners with disorders, learners with difficulties and learners with disabilities

\subsection{Slow learners}

It is accepted that all children or adults learn at different rates. Yet, some persons though slow learners do not have a learning deficiency. Slow-learners fail in their studies, regardless of the level of education, because of their low intellectual abilities. They may have a wide range of abilities and a variety of characteristics depending on their background. 


\subsubsection{Characteristics}

According to Haskvitz, A., (2011)

- First, slow learners are frequently immature in their relations with others and do poorly in school.

- Secondly, they cannot do complex problems and work very slowly.

- They lose track of time and cannot transfer what they have learned from one task to another well.

- They do not easily master skills that are academic in nature, such as the times tables or spelling rules.

- Perhaps the most frustrating trait is their inability to have long-term goals.

- In their physical appearance they are not different from normal children.

- Capable of being educated in ordinary schools and achieve a moderate success provided

- They are allowed to proceed at a slower pace.

- They are not capable for higher education

- They have poor memories

\subsection{Learning disorders}

According to the Encyclopedia of Children's Health Learning Disorders, these disorders are academic difficulties experienced by children and adults of average to above intelligence. People with learning disorders have difficulty with reading, writing, mathematics or combination of the three. These difficulties significantly interfere with academic achievement or daily living.

\subsubsection{Characteristics}

- $\quad$ Reading disorder: It is a language related disorder coming in four types

- Some people decode fine but do not comprehend.

- Some people have a hard time decoding but comprehend well.

- Some others have both problems.

- $\quad$ Some people do not recognize or interprete letters and words (dyslexia)

- Children have problems recognizing and counting numbers (dyscalculia)

- Disorders of written expression typically occur in combination with reading or mathematics. It is characterized by problems with spelling, punctuation, grammar, and organizing their thoughts in writing. (dysgraphia)

As it is, learning disorders affect how a person understands, remembers and responds to new information. People with learning disorders may have problems one or more of the following problems (Mediline Plus (2011).

- Listening or paying attention.

- Speaking.

- Reading or writing.

- Doing math. 


\subsection{Learning difficulties}

Within the spectrum of difficulties associated with cognition and learning the Code of Practice the following are identified: (SENCO, 2010)

\subsubsection{Characteristics}

- $\quad$ Specific learning difficulties. (SpLD)

- Moderate learning difficulties.

- $\quad$ Severe and multiple learning difficulties.

- Sub-groups of SpLD can be considered: Dyslexia, Dyscalculia, Dyspraxia.

\subsection{Learning disabilities}

Learning disabilities are problems that affect the brain's ability to receive, process, analyze, or store information. These problems can make it difficult for a student to learn as quickly as someone who is not affected by learning disabilities (Mediline Plus (2011).

The following is a list of common characteristics of an LD student. Conditions must be persistent over a long period of time. Presence of these conditions does not necessarily mean a person is learning disabled.

\subsubsection{Reading skills}

- Poor decoding skills

- Poor reading fluency

- Slow reading rate

- Lack of self-monitoring reading skills

- Poor comprehension and/or retention

- Difficulty identifying important ideas in context

- Extreme difficulty building ideas and images

- Difficulty integrating new ideas to existing knowledge

- Weak vocabulary skills

- Extreme difficulty understanding words or grammar

- Difficulty recognizing high frequency words

- Oral comprehension is noticeably stronger than reading comprehension

- Extreme difficulty focusing attention on the printed marks

- Difficulty controlling eye movements across the page

- Wavy or shimmering pages not attributable to poor vision

\subsubsection{Spelling skills}

- Phonological awareness is noticeably stronger than spelling ability

- Frequent spelling errors of high frequency words

- Extreme difficulty with homonyms and/or regular spelling patterns

- No understanding of the relationship of phonics to written language

- No understanding of common spelling rules

- Inadequate understanding of phonics even with instruction 


\subsubsection{Written expression skills}

- $\quad$ Poor writing fluency

- Unable to compose complete, grammatical sentences

- Difficulty organizing written information

- Poor handwriting

- Extremely poor alignment

- Inability to take notes or copy information from a book or the board

- Oral expression is noticeably stronger than written expression

- Extremely weak proofreading skills

\subsubsection{Oral language skills}

- Inability to hear small differences between sounds, not attributable to a hearing loss, particularly vowel sounds

- Difficulty articulating thoughts or ideas orally

- Difficulty pronouncing words

- Inability to blend sounds together to form words

- Difficulty listening and responding to a series of directions

- Disorganized recall of facts or details

\subsubsection{Mathematical skills}

- Poor mathematical fluency

- Difficulty memorizing multiplication tables

- Difficulty identifying multiples and/or factors

- Poor basic calculation skills

- Difficulty understanding word or application problems

- Poor understanding of mathematical concepts

- Difficulty sorting out irrelevant information

- Lower visual perceptual and visual-spatial ability

- Inability to transfer basic mathematical concepts to solve problems with unpredictable information

- Inability to use basic facts within more complex calculations

\subsubsection{Memory skills}

- Extremely weak ability to store and retrieve information efficiently

- Extremely weak ability to hold information for immediate use

\subsubsection{Reasoning skills}

- Extremely weak ability to solve problems, particularly when information or procedure is unfamiliar.

- Extreme difficulty recognizing, transforming, or using specific information to reach general conclusions. 


\section{Causes of learning impairments}

\section{- Slow Learners}

Quite often slow learners are confused with reluctant learners. It is claimed that though they are willing to learn, they have problems with the process. This is due to four specific factors (Table 3)

\begin{tabular}{|l|l|l|l|}
\hline Psychological & School problems & Health Problems & Family Problems \\
\hline $\begin{array}{l}\text { Deprived } \\
\text { Culture }\end{array}$ & Medium Instruction & Defective vision & Illiterate parents \\
\hline Absenteeism & Untrained Teachers & Poor health & Busy parents \\
\hline $\begin{array}{l}\text { Emotional } \\
\text { Growth }\end{array}$ & $\begin{array}{l}\text { Inadequate teaching } \\
\text { staff }\end{array}$ & $\begin{array}{l}\text { Physical } \\
\text { impairments }\end{array}$ & $\begin{array}{l}\text { Low cultural } \\
\text { background }\end{array}$ \\
\hline & Violence in School & & Hereditary reasons \\
\hline & Resource problems & & Low environment \\
\hline & Contact with peers & & Family size \\
\hline
\end{tabular}

Table 3. Factors influencing slow-learners Source: Author's research team.

- $\quad$ Learning Disorders

- Neurological abnormalities

- Brain infections

- Visual problems

- Language processing

- Attention deficit

- Medical conditions

- $\quad$ Learning Difficulties

- Pre-natal (example Down syndrome)

- Per-natal ( oxygen deprivation, cerebral palsy)

- Post-natal (example Meningitis)

- $\quad$ Learning Disabilities

- Genetic Influences

- Brain Development

- Environmental impacts

\section{Prevalece}

Prevalence in no way can be considered a reliable indicator. Determining the number of children with disabilities with accuracy is not feasible. Parents are reluctant to have their children identified to having disabilities and tend to consider such classification as a family stigma. Moreover in most cases they are unaware of such situations. At the moment, the 
estimated population with disabilities in EU27 is 42.9 million or the $8.56 \%$ of the total population. The respective figures of the EuroArea 16 is 24.42 million or $7.41 \%$

People with disabilities often encounter attitudinal and environmental barriers which do not allow their full active and equal participation in society. UNO officials have stated that persons with disabilities are the "World's larger minority". The fact that a fifth of the working age is unemployed due to disabilities is a critical issue in as much as it is accepted that many disabled people are able to work if they are given the proper support Statistical data (Eurostat, 2010) reveal that persons with disabilities in the EU27 are in employment by $42.3 \%$ as compared with non-disabled persons who are employed by $64.6 \%$ (Table 4 ).

\begin{tabular}{|l|l|l|l|l|}
\hline Category & 2000 & 2003 & 2006 & 2009 \\
\hline $\begin{array}{l}\text { Employment } \\
\text { total 15-64 }\end{array}$ & $62.2 \%$ & $62.6 \%$ & $64.5 \%$ & $64.6 \%$ \\
\hline $\begin{array}{l}\text { Employment } \\
\text { total 55-64 }\end{array}$ & $36.9 \%$ & $40.0 \%$ & $43.5 \%$ & $46.0 \%$ \\
\hline $\begin{array}{l}\text { Disabled } \\
\text { Persons } \\
15-64\end{array}$ & $38.7 \%$ & $39.6 \%$ & $42.0 \%$ & $42.3 \%$ \\
\hline
\end{tabular}

Table 4. Employment rates jn EU27, 2009, source: Eurostat.

The fact that definitions about persons with the various types of learning disabilities have created confusion has hindered the appropriate implementation of measures and programmes in professional, social and educational sectors. Estimates show that about 10$20 \%$ of all persons have learning disorder, about $2-10 \%$ of children have a reading disorder and about 1-6\% have an arithmetic disorder. Unfortunately the availability of high quality, internationally comparable data on disability that is important for the planning, implementation, monitoring and evaluation of inclusive policies is often not available. Data vary from under $1 \%$ in Kenya and Bangladesh to $20 \%$ in New Zealand. Overall, disabled people represent a significant proportion of the world population.[12 ] The following tables represent the percentage of disabled persons in selected countries based on censuses and surveys after the year 2000. European countries not included in this table do not provide data from 2000 onwards.

\begin{tabular}{|l|c|c|}
\hline Source: Surveys & & \\
\hline Country & year & $\%$ Population \\
\hline Australia & 2000 & $20.0 \%$ \\
\hline Zambia & 2006 & $13.1 \%$ \\
\hline Ecuador & 2005 & $12.1 \%$ \\
\hline Nicaragua & 2003 & $10.3 \%$ \\
\hline
\end{tabular}

Table 5. People with disabilities, source Eurostat 


\begin{tabular}{|l|c|c|}
\hline Source: Censuses & & \\
\hline Country & Year & \% Population \\
\hline United States & 2000 & $19.4 \%$ \\
\hline Canada & 2001 & $18.5 \%$ \\
\hline Brazil & 2000 & $14.5 \%$ \\
\hline Uganda & 2001 & $3.5 \%$ \\
\hline Mexico & 2000 & $2.3 \%$ \\
\hline India & 2001 & $2.1 \%$ \\
\hline
\end{tabular}

Table 6. People with disabilities, source Eurostat

Children with learning difficulties are estimated to be about $17.6 \%$ with lowest rate $12.6 \%$ and children accommodated in hospitals $38.2 \%$ [13]. Whereas these data refer to a single district in USA further surveys confirm that, almost, in all districts the data are the same with a minor deviation. Finally, the situation with slow learners is rather complicated since persons characterized as being slow in achievement are not necessarily in the category of disabled persons and statistical data are not quite reliable. However, findings from USA reveal that in typical schools the percentage of slow-learners is something between $12 \%$ and $16 \%$. Yet, in a class in areas of poverty and low income urban areas the percentage is between $24 \%$ and $32 \%$

\section{Measurement of intelligence (I.Q.)}

As of a custom, when referring to a disabled person the first criterion is the IQ score. Whether we like it or not, IQ test is a tool which can enable us to draw results based on measurable data. Indeed, it is true to say that the diagnostic practice has been debated, disputed and criticized. [14], in the case of identifying the type and degree of learning impairments. Apart from the fact that a neurological dysfunction has never been proved as being by $100 \%$ the cause of learning disorder, yet,it is a message that cannot be entirely neglected. Therefore, an IQ score can indicate to psychologists, educators and teachers the pathway to the category of impairment.The following table presents a descriptive classification of IQ scores (Table 7).

\begin{tabular}{|l|l|c|}
\hline IQ score & Description & \% of population \\
\hline $\mathbf{1 3 0}+$ & Very superior & $\mathbf{2 . 2} \%$ \\
\hline $120-129$ & Superior & $6.7 \%$ \\
\hline $110-119$ & High average & $16.1 \%$ \\
\hline $90-109$ & Average & $50.0 \%$ \\
\hline $80-89$ & Low average & $16.1 \%$ \\
\hline $70-79$ & Borderline & $6.7 \%$ \\
\hline Below 70 & Extremely low & $2.2 \%$ \\
\hline
\end{tabular}

Table 7. Classification of IQ scores,, source Wechsler's scale 
Apparently, the IQ scores give a global indication of the occupations a person can follow for a life long career. (Wilson,G., \& Gylls,D.(2004).

\begin{tabular}{|c|l|l|l|}
\hline $\begin{array}{c}\text { IQ } \\
\text { SCORES }\end{array}$ & $\begin{array}{c}\text { OCUUPATION ACCORDING TO } \\
\text { IQ }\end{array}$ & $\begin{array}{c}\text { IQ } \\
\text { SCORES }\end{array}$ & $\begin{array}{c}\text { OCCUPATION ACCORDING } \\
\text { TO IQ }\end{array}$ \\
\hline 160 & Professors, Researchers & $100+$ & Machine Operators, Shopkeepers \\
\hline 140 & Senior Civil Servants & $100-$ & Warehousemen, Bakers, Drivers \\
\hline 130 & Scientists, Lawyers & 90 & Laborers, Gardeners, Miners \\
\hline 120 & School Teachers, Managers, Nurses & 70 & Auxiliary Services \\
\hline 110 & Clerks, Telephone Operators & Below 70 & Unskilled workers \\
\hline
\end{tabular}

Table 8. Classification of occupations according to IQ, source OECD

The above classification has been slightly adopted according to IQ normal curve based on Wechster IQ scale and Stanford Binet IQ scale .

The IQ score is one part of the factors which are taken into consideration for defining the various disabilities. Though much interest is attached to the intelligence factor, Siegel, L.,(2009) supported that intelligence tests and IQ scores are not necessary for defining learning disability She further examined four assumptions of the use of IQ scores in the definition of learning disabilities. These assumptions were:

- $\quad$ IQ tests measure intelligence.

- Intelligence and achievement are independent.

- IQ scores predict reading, and children with low IQ scores should be poor readers.

- Children who have reading problems with different IQ scores have different cognitive processes and information skills.

Though the reliability of the IQ Normal Curve (fig.1) is disputed by certain scientists, it is still regarded a useful tool for measuring the IQ score of individuals for academic, professional or psychological reasons

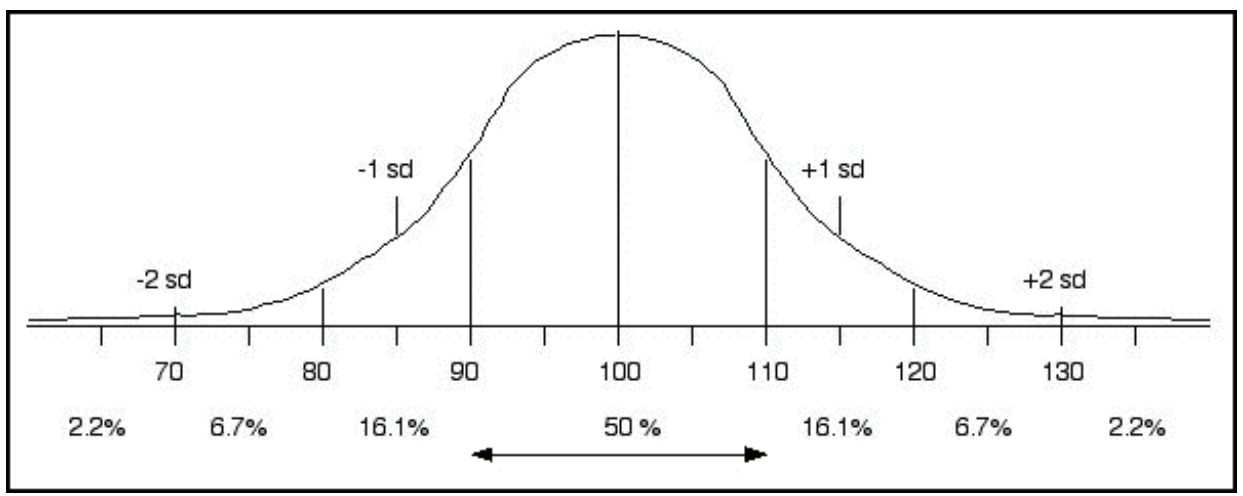

Fig. 1. Measurements of Intelligence 
In the process of her surveys Siegel noticed that some children with low IQ scores can be good readers. Then, on logical and empirical grounds it was concluded that IQ test scores are not necessary for the definition of learning disabilities.Back to the table 9 to consider the differences of IQ scores related to the various types of learning impairments.

\begin{tabular}{|l|l|}
\hline IQ scores for various learning impairments \\
\hline RANGE & Type of impairment \\
\hline $71-85$ & SLOW LEARNERS \\
\hline 70 or less & LEARNING DISABILITIES \\
\hline $50-70$ & Mild Learning Disabilities \\
\hline $35-49$ & Moderate Learning Disabilities \\
\hline $20-34$ & Severe Learning Disabilities \\
\hline Less than 20 & Profound \\
\hline Various & LEARNING DISORDERS DIFFICULTIES \\
\hline $70-65$ & Moderate Learning Difficulties \\
\hline $64-40$ & Severe Learning Difficulties \\
\hline Below 40 & Profound, multiple Learning Difficulties \\
\hline
\end{tabular}

Table 9. Classification of learning impaired people according to IQ, source Hallahan, D., \& Kauffman .J.

\section{Employability of people with disabilities}

People with disabilities often encounter attitudinal and environmental barriers which do not allow their full active and equal participation in society. The fact that a fifth of the working age is unemployed due to disabilities is a critical Issue. In as much as it is accepted that many disabled people are able to work if they are given the proper support. Statistical data (Eurostat, 2010) reveal that persons with disabilities in the EU27 are employed by $42.30 \%$ as compared with non-disabled persons who are employed by $64.60 \%$ (Table 10). Evidently, the unemployment rates between disabled and non-disabled persons are dramatically unbalanced. (Table 11)

\begin{tabular}{|l|l|l|l|l|}
\hline Category & 2000 & 2003 & 2006 & 2009 \\
\hline $\begin{array}{l}\text { Employment } \\
\text { total 15-64 }\end{array}$ & $62.2 \%$ & $62.6 \%$ & $64.5 \%$ & $64.6 \%$ \\
\hline $\begin{array}{l}\text { Employment } \\
\text { total 55-64 }\end{array}$ & $36.9 \%$ & $40.0 \%$ & $43.5 \%$ & $46.0 \%$ \\
\hline $\begin{array}{l}\text { Disabled } \\
\text { Persons } \\
15-64\end{array}$ & $38.7 \%$ & $39.6 \%$ & $42.0 \%$ & $42.3 \%$ \\
\hline
\end{tabular}

Table 10. Employment rates between 2000-2009, source Eurostat, 2010. 


\begin{tabular}{|l|c|c|}
\hline Status & $\begin{array}{l}\text { EU27 million } \\
2009\end{array}$ & $\begin{array}{c}\text { EU27 million } \\
2010\end{array}$ \\
\hline Total population & 502.8 & 501.00 \\
\hline $\begin{array}{l}\text { Unemployed } \\
\text { non-disabled }\end{array}$ & $8.9 \%$ & $9.7 \%$ \\
\hline $\begin{array}{l}\text { Youth } \\
\text { non-disabled }\end{array}$ & $19.5 \%$ & $20.5 \%$ \\
\hline $\begin{array}{l}\text { Unemployed } \\
\text { Youth disabled }\end{array}$ & $49.2 \%$ & $53.2 \%$ \\
\hline
\end{tabular}

Table 11. Non-disabled VS disabled unemployed youth, source Eurostat.

Apart from the public assistance and the Active Labour Market Policies (ALMP) which are provided by EU27 to support employed persons with disabilities, at a percentage of $16.3 \%$ (Euro 7.233 million) in 2006 (Eurostat database, 2010) a basic factor which reduces the unemployment rates of persons with disabilities is the level of education. The lower the level of education the higher the rate of unemployment (Table 12).

\begin{tabular}{|l|c|c|c|}
\hline Work status & Lower Level & Medium Level & Higher Level \\
\hline Activities & $31.6 \%$ & $56.3 \%$ & $69.7 \%$ \\
\hline Employment & $25.3 \%$ & $48.5 \%$ & $61.7 \%$ \\
\hline Unemployed & $19.9 \%$ & $13.3 \%$ & $11.4 \%$ \\
\hline
\end{tabular}

Table 12. Educational level and unemployment, source Eurostat, 2010)

\section{Conclusion}

The increased economic crisis in our era has dramatic influence in all sectors. Indicators reveal that whereas the world population will increase in the next 20 to 40 years by 2.593 million the increase of population in the EU27 countries is minimal. In parallel, the rates of unemployment are considerably disproportionate between disabled and non-disabled persons. There is, also, a quite unbalanced relationship between unemployed persons graduates of lower and upper secondary education and tertiary education. The rate of unemployed persons of lower secondary level raised from 2007 to 2009 by 47\%, of upper secondary level by $25 \%$ and of tertiary level by $32 \%$

The problems identified are related to an unbalanced relationship between unemployed disabled and non-disabled persons, educational attendance and social security expenditure.

Yet, the most important problem is the terminology used to describe persons with disabilities which is linguistically, psychologically and socially inappropriate. As a result, prevalence data are highly disputed preventing the implementation of the required measures and the effective communication between professionals, parents and disabled persons. In the sector of learning disabilities, which should be changed to learning impairments to avoid confusion between the general term and one of the types of learning impairments, the use of terms which are not clearly expressed should be given adequate 
consideration. Since, every type of disability is linked to the IQ score of disabled persons, attention to the use and usage of terms is both important and necessary.

\section{Recommendations}

The situation requires immediate consideration and measurements in a multi-dimensional setting. The unemployment rates of persons with disabilities must decrease. It is necessary that these persons are included in the normal social setting as much as possible in order to contribute to the efforts of economic recovery which, also, will result to the reduction of public expenditure on supporting projects..

The problem of the use of disputable terms in describing and/or classifying persons with disabilities is extremely important, mainly in the sector of learning impairments, since situations like slow learners, learners with difficulties, learners with disorders and learners with disabilities, though seemingly identical they are characterized by substantial differences among them, which necessitate appropriate measures for dealing with them..

The terms of classification should be substituted by the appropriate ones. The provisions established by UNO (2006) and other organizations should be followed

Though a number of disabled persons are employed, barriers to employment should be prevented.

The social model of disability, implemented in UK should be considered. Under this model, persons with intellectual or psychological variations are not always considered to be disabled.

\section{References}

Alton,, G. (2001). The History of Special Education in America. Demand Media, Inc. USA

Anastasi, A. ( ed. 1966) Testing Problems in Perspective, Washington DC. American Council of Education.

Chandler, J (2010) Learning Disorders, Learning Disabilities,,LoveToKnow,Corp.USA Available from http://www.klis.com/chandler/pamphlet/learning/learning pamphlet.htm

Encyclopedia of Children's Health: Learning Disorders (2011)

Hallahan, D. \& Kauffman, J. (1978). Exceptional Children: Introduction to Special Education, Prentice HALL, Inc. ISBN 0-13-293944-4, Englewood Cliffs, N.J.

Harris, B. (2008).The Nature and extent of aggressive behavior amongst people with learning disabilities in a single health district, JIDR, Journal of Intelligent Disability, vol.37,issue 3, first published on line 28-06-2006.

Haskvitz, A. (2011) Helping your slow-learner child Horace Mann, Reach Every Chid. Available from http://www.reacheverychild.com/feature/slowlearners/html

Heward, W. \& Orlansky, D.(1980).Exceptional Children (Bell \& Howwell Company), Charles E. Merrill Publishing Company ISBN 0-675-08179-3, USA

Mablett, D. (2002) Disabilities Categories in European Social Policy. Definition \& Disability in Europe, A Comparative Analysis prepared by Brunel University, UK.

Mandy, D. ( 2009 ) The art of communication. Basic Principles of effective communication. Helium (where knowledge rules) Available from http://www.helium.com/ 
Mediline Plus (2011) Learning Disabilities. National Institute of Neurological Disorders and Strock, Rockville Pike, USSA

Mont, D. (2007) Measuring Disability Prevalence, Special Protection SP Discussion Paper No 0706, The World Bank available from www.worldbank.org.sp

Pale, B. (2010): An Overview of Caring For People With Disabilities, TRCB .com (The Red carpet Broadcast) http:/ / phamaly-colorado.org/

SENCO (2011) Characteristics of cognitive and learning difficulties. Help Sheet 2, teachingexpertise. Available from http://www.teachingexpertise.com/

Siegel, L.S. (2009): IQ is irrelevant to the definition of Learning Disabilities, Published US National Library of Medicine. National Library of Medicine, National Institutes of Health.

Wilson, G. \& Gylls, D. (2004) Know Your Child's IQ available from http://iqtest.learninginfo.org/ig04.htm

Winzer, M., (1993). The History of Special Education. From Isolation to Integration, Gallauded University Press, Washington, DC. 20002, available from books.google.gr/books?isbn=1563680181

Yell, M.L. (2006). The Legal History of Special Education. Journal of Disability Policy Studies. (NARIC) National Rehabilitation Information Center. 


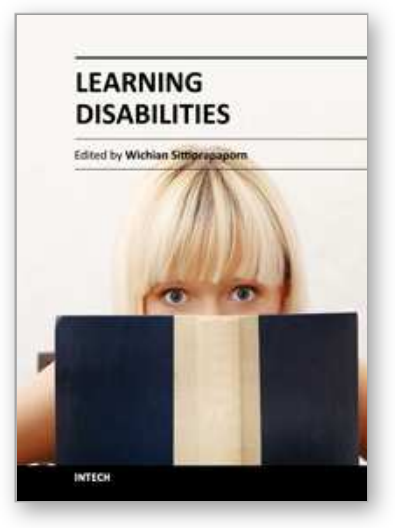

\author{
Learning Disabilities \\ Edited by Dr. Wichian Sittiprapaporn
}

ISBN 978-953-51-0269-4

Hard cover, 364 pages

Publisher InTech

Published online 14, March, 2012

Published in print edition March, 2012

Learning disability is a classification that includes several disorders in which a person has difficulty learning in a typical manner. Depending on the type and severity of the disability, interventions may be used to help the individual learn strategies that will foster future success. Some interventions can be quite simplistic, while others are intricate and complex. This book deserves a wide audience; it will be beneficial not only for teachers and parents struggling with attachment or behavior issues, but it will also benefit health care professionals and therapists working directly with special needs such as sensory integration dysfunction.

\title{
How to reference
}

In order to correctly reference this scholarly work, feel free to copy and paste the following:

George S. Mouzakitis (2012). Language Disabilities: Myths and Misconceptions vs. Reality, Learning Disabilities, Dr. Wichian Sittiprapaporn (Ed.), ISBN: 978-953-51-0269-4, InTech, Available from: http://www.intechopen.com/books/learning-disabilities/language-disabilities-myths-and-misconceptions-vsreality

\section{INTECH}

open science | open minds

\section{InTech Europe}

University Campus STeP Ri

Slavka Krautzeka 83/A

51000 Rijeka, Croatia

Phone: +385 (51) 770447

Fax: +385 (51) 686166

www.intechopen.com

\section{InTech China}

Unit 405, Office Block, Hotel Equatorial Shanghai

No.65, Yan An Road (West), Shanghai, 200040, China

中国上海市延安西路65号上海国际贵都大饭店办公楼 405 单元

Phone: +86-21-62489820

Fax: +86-21-62489821 
(C) 2012 The Author(s). Licensee IntechOpen. This is an open access article distributed under the terms of the Creative Commons Attribution 3.0 License, which permits unrestricted use, distribution, and reproduction in any medium, provided the original work is properly cited. 